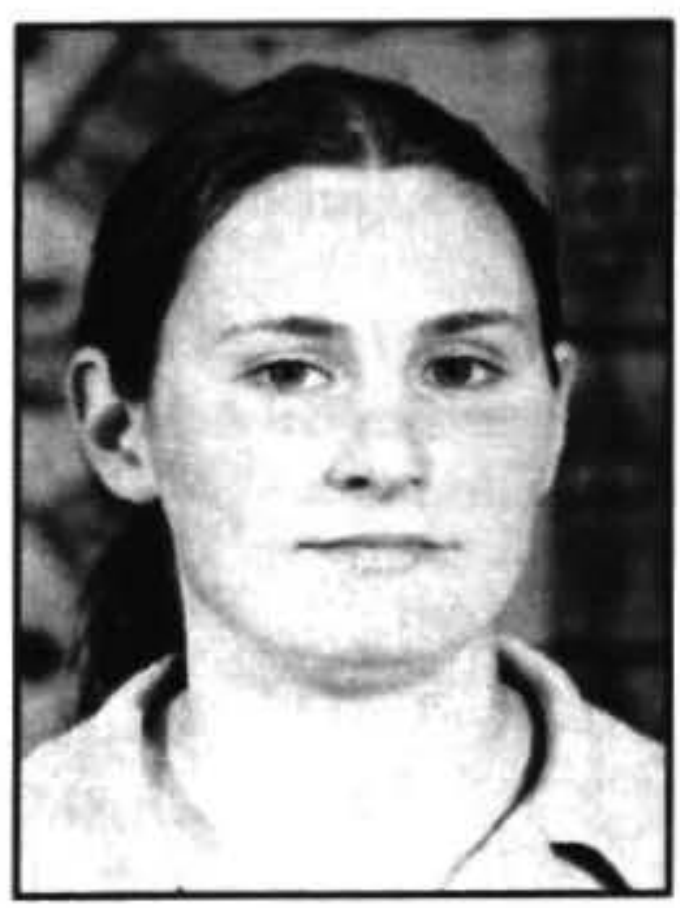

\title{
AN ANALYSIS OF DISPARITY BETWEEN PACIFIC AND NON-PACIFIC PEOPLES' LABOUR MARKET OUTCOMES IN THE HOUSEHOLD LABOUR FORCE SURVEY
}

\author{
Janet Humphris
}

\author{
Labour Market Policy Group \\ Department of Labour
}

\author{
Simon Chapple
}

Ministry of Social Policy

\begin{abstract}
Disparity in employment outcomes between Pacific and non Pacific people is higher today than it was in 1985. The disparity in the employment rate increased substantially between 1986 and 1991, though has been decreasing slowly since. This paper attempts to find reasons for changes in employment rate disparity using cross-tabulated information from the Household Labour Force Survey on region, educational attainment, occupation, industry, length of time lived in New Zealand and working age population size. Our research suggests that a key reason for the increase in disparity was over-representation of Pacific people in sectors that were disproportionately affected by changes in labour demand in the late 1980s. In particular, there was decreasing demand for workers in the manufacturing industry, workers in the occupational grouping 'production and related workers' and workers with no educational qualifications. Higher Pacific population growth may also at times have had an impact on employment disparity.
\end{abstract}

Keywords: Pacific people, household labour force survey, employment disparity

On average, Pacific peoples experience poorer labour market outcomes than non-Pacific people. For example, in the March 2000 quarter Pacific people had a higher unemployment rate than the rest of the population ( $12.3 \%$ compared to $6.4 \%)$, a lower participation rate $(61.4 \%$ compared to $65.7 \%$ ) and a lower employment rate $(53.9 \%$ compared to $61.5 \%$ ). In addition, for those who are earning, Pacific men had an average hourly wage of $75.6 \%$ and Pacific women had an average hourly wage of $83.9 \%$ of their Pakeha/ European counter-parts. Little analytical work has been done to examine the time series patterns and reasons for these disparities in outcomes between Pacific and nonPacific peoples.

This paper analyses disparity in labour market outcomes by examining the employment rate gap between Pacific people and the rest of the population. We use quarterly data from the Household Labour Force Survey (HLFS) to measure employment rate disparity and examine how it changes over time. The paper shows that the employment disparity between Pacific and non-Pacific people has increased substantially since the middle of the $1980 \mathrm{~s}$, and attempts to find reasons for this increase. To do so the paper uses cross-tabulated information on region, educational attainment, occupation, industry, length of time lived in New Zealand, age and size of working age population. The paper takes a similar methodological approach to Chapple (1999), which examines disparity between Maori and non-Maori.

The data used in the paper covers the period 1986-1999. The key measure of labour market outcomes used is the employment rate. The employment rate is used rather than unemployment rate as it is a better summary measure of labour market disparity for a variety of reasons (see Chapple and Rea 1998). In particular using employment rate data means we have less sample error than if unemployment rate was used, as the sample of people who are employed is larger than the sample of people who are unemployed. Minimising sampling error is important, as the total number of Pacific people measured in the Household Labour Force Survey is small.

The paper begins by reviewing previous research on $\mathrm{Pa}$ cific peoples' labour market outcomes. It then outlines how the demographic characteristics and employment outcomes 
of Pacific peoples have changed between 1986 and 1999. The main part of the paper analyses possible explanations for changing relative employment outcomes. Beginning with the supply side, variables such as age, education, length of time lived in New Zealand and population growth are examined to see if they affect relative Pacific employment chances. The next part of the paper examines labour demand to see if changing demand in sectors where $\mathrm{Pa}$ cific people were over-represented had a disproportionate effect on Pacific employment outcomes. Demand changes are examined over four dimensions: region, industry, occupation and educational qualifications.

\section{Socio-demographic Characteristics and Com- position of the Pacific Population}

Pacific peoples are not a homogeneous group. Although Pacific peoples share many commonalities, it is worth remembering that the Pacific population is made up of groups with different nationalities, histories, values and cultures. In addition, different groups vary in population size and location within New Zealand.

Table 1 gives an overview of some of the socio-demographic differences between different Pacific groups in New Zealand, using data from the 1996 census. average around 20 years in New Zealand. The latter group are thus much more likely to be New Zealand born.

On average the Pacific group is likely to have more working age people without qualifications than New Zealand as a whole. Samoans are the least likely to be without qualifications and Tokelauans are the most likely. Fijians are particularly well qualified but are a very small percentage of the total Pacific population.

Similarly, while the main Pacific groups have a lower employment rate than the population at large, Samoans have a much higher employment rate than the Tokelauans or Tongans. Again Fijians standout as having better employment outcomes than the population at large.

In the analysis below the separate Pacific groups are combined together as one aggregate group. This aggregation is in part because of cultural and socio-demographic similarities between different Pacific peoples, which have been mentioned above. In addition aggregation is forced upon us as a consequence of the small sizes of individual Pacific population samples in the HLFS. The total number of Pacific people sampled in the Household Labour Force Survey is quite small, less than $5 \%$ of the total sample. If we disaggregate the Pacific group further into individual

\section{Table 1. Key Demographic Statistics for Different Pacific Groups, 1996 Census}

\begin{tabular}{|c|c|c|c|c|c|c|}
\hline & $\begin{array}{c}\text { Population } \\
\text { size }\end{array}$ & $\begin{array}{c}\text { Share of total } \\
\text { Pacific } \\
\text { population } \\
\end{array}$ & Median Age & $\begin{array}{c}\text { Median } \\
\text { Years in New } \\
\text { Zealand }\end{array}$ & $\begin{array}{l}\text { Percentage of } \\
\text { WAP with no } \\
\text { qualifications }\end{array}$ & $\begin{array}{c}\text { Employment } \\
\text { rate }\end{array}$ \\
\hline Samoan & 83,718 & 48.3 & 20.2 & 12.4 & 43.3 & 54.2 \\
\hline Cook Island Maori & 34,167 & 19.7 & 18.7 & 21.4 & 54.3 & 51.1 \\
\hline Tongan & 26,061 & 15.0 & 18.9 & 9.7 & 46.5 & 50.2 \\
\hline Niuean & 14,712 & 8.5 & 19.6 & 21.5 & 49.9 & 54.8 \\
\hline Fijian & 6,657 & 3.8 & 23.6 & 9.4 & 26.8 & 62.2 \\
\hline Tokelauan & 4,461 & 2.6 & 19.3 & 20.9 & 50.8 & 45.2 \\
\hline Other Pacific & 3,408 & 2.0 & 24.2 & 5.2 & 27.4 & 49.8 \\
\hline Rest of Population & $3,445,119$ & $\mathrm{~N} / \mathrm{a}$ & $33.0^{*}$ & $\mathrm{~N} / \mathrm{a}$ & 31.6 & 58.8 \\
\hline
\end{tabular}

*This number is for the total population. A figure which excluded Pacific peoples from the total was not available

Samoans alone make up half of the Pacific population, while Cook Islanders make up about one in five of the group. Tongans and Nuieans together make up another quarter. While these are all distinct regions, it is noteworthy that all these groups (as well as Tokelauans) are Polynesian with similar traditional languages and cultures.

The main Pacific sub-populations all have considerably younger age structures than the rest of the population. The median age for the main sub-groups is in the early $20 \mathrm{~s}$ compared to 33 for the population at large.

While sharing a common low median age, some Pacific peoples are more recent immigrants than others. Samoans and Tongans average around 10 years in New Zealand compared to Nuieans, Tokelauns and Cook Islanders who
Pacific populations, the samples used will be too small to carry out a valid analysis. That said, there may be some future potential to divide the Pacific group into say Samoan people and other Pacific people, especially given the fact that of the major groups Samoans generally perform somewhat better than other Pacific peoples.

A final point to make is that average Pacific socio-demographic outcomes are often very similar to Maori outcomes. Indeed, there are many similarities between the situations of the two groups. Both groups are Polynesian in traditional culture. Pacific Island and Maori people both migrated from peripheral rural economies into the cities in the post-war period. Maori migrated within New Zealand from country into town post-Second World War, while 
Pacific Island people migrated from island archipelagoes into New Zealand towns. In many cases the current labour market issues faced by the two populations reflect common problems faced by unskilled migrants in towns the world over. In some cases, given the migration rights of some Pacific Islanders, the decision to migrate from Northland to Auckland or from East Cape to Wellington for a Maori is in most ways directly analogous to a decision to migrate from Aitutaki, Apia or Niue to Auckland.

Table 2 shows that those groups who have automatic right of access to New Zealand (Cook Islands, Niue and Tokelau) have many more of their ethnic populations in New Zealand as opposed to their "home" island. Groups having no automatic right of access, like Tonga and Samoa, have a much lower proportion in New Zealand. Given the vast majority of Pacific peoples in New Zealand are urbanised in the Auckland urban area and that living conditions in the home islands are very much in a village setting, the numbers in table 2 can also be considered rough and ready indices of rural-urban splits for Niueans, Tokelauans and Cook Islanders.

\section{Table 2. Proportion of Each Pacific Group in New Zealand Compared to "Home" Island Population + New Zealand Population}

\begin{tabular}{lc}
\hline Ethnicity & Percent \\
\hline Samoan & $37.3 \%$ \\
Cook Island Maori & $71.2 \%$ \\
Tongan & $24.3 \%$ \\
Niuean & $89.9 \%$ \\
Fijian & $1.0 \%$ \\
Tokelauan & $83.1 \%$ \\
\hline
\end{tabular}

Source: derived from Cook, Didham and Khawaja (2000, p. 21)

One big difference between Maori and the Pacific People who have citizenship rights in New Zealand is that New Zealand welfare benefits are not available for Cook Islanders, Niueans and Tokelauans who return back to their traditional areas following a spell in the New Zealand labour market. For the other major Island sub-populations in New Zealand, like Samoans, Tongans, and Fijians, there is no current automatic right of access into the New Zealand labour market (although there has been for Samoans in the past). Indeed, Pacific people living in traditional areas are not automatically part of the New Zealand labour market.

The main sub-groups of Pacific peoples share relatively high fertility rates compared to the general population (Maori are somewhere between the Pacific fertility rate and that of the general population). Lastly, again like Maori, Pacific people have high rates of exogamy (marriage outside the broad ethnic group), although the extent of $\mathrm{Pa}$ cific out-marriage seems to be lower than out-marriage is for Maori, especially in terms of marriage of the respective groups to Pakeha/European (see Chapple 1999 on rates of Maori exogamy; and Statistics New Zealand 2000, p. 62 on attributed single and multiple ethnicity of live births by child, a good indication of relative intermarriage).

\section{Pacific People in the Labour Market: The Literature}

The vast majority of research on Pacific people in the labour market has been descriptive, drawing on the census or, more rarely, the HLFS for information. This review focuses discussion on the non-descriptive studies.

Typical of much of the descriptive work is the report on the Social and Economic Status of Pacific people in New Zealand which notes that in 1996 Pacific people had an unemployment rate of $15.3 \%$ compared with $15.5 \%$ for Maori and $4.6 \%$ for European Pakeha. Similarly, Labour force participation rates in 1996 were $61.0 \%$ for Maori, 66.2\% for European Pakeha and $58.8 \%$ for Pacific people. This was a drop from a high of $70 \%$ participation in 1987. It is also noted that of those Pacific people who are employed, the majority are employed in low socio-economic status position in occupations such as Plant and Machine Operators, Elementary Occupations and Sales and Service Workers.

Fletcher (1995) and Krishnan (1994) suggest that the younger age distribution and lack of qualifications among Pacific peoples may influence employment outcomes. However, they both note that when the data is adjusted to take age and education effects into account, Pacific people still have a higher rate of unemployment and lower rate of employment than non-Pacific people for each age group or level of qualifications held.

Krishnan (1994) uses data from the 1986 and 1991 censuses to examine Pacific labour market outcomes. This study also finds that Pacific people have lower participation and employment rates and higher unemployment rates than the rest of the population, and that disparity in outcomes increased between 1986 and 1991 . Total employment contracted by $7 \%$ between 1986 and 1991 . Over the same time period, employment among Pacific people contracted by a disproportionately large $10 \%$. It is suggested that this was due to a decrease in employment in the secondary sector, which disproportionately affected Pacific people. Between 1986 and 1991 employment in the secondary sector fell by $25 \%$ while employment in the service sector grew by $2 \%$. At the time of the 1986 census most Pacific people were employed in unskilled or semiskilled occupations in the secondary sector. For example, $63 \%$ of Pacific males were employed as production/transport/equipment operators and labourers compared with $37 \%$ of all male workers.

Fletcher (1995, p. 127) suggests that declining participation among Pacific people may be due to changing demand for labour, more specifically a 'decline in employ- 
ment over the inter-censal period, and especially...job losses in the manufacturing sector which employed many Pacific Islands workers.' Fletcher (1995, p. 128) notes that 'there has in fact been a trend over the last twenty years from secondary sector employment towards the services sector' particularly marked among women and the New Zealand born.

Using data from the Household economic survey, Dixon (1996a) finds that mean real hourly wages of the 'other' ethnic group (of which more than half are Pacific people) dropped by $14.8 \%$ between 1984 and 1994 from $\$ 14.03$ to $\$ 11.95$. Over the same time period, Pakeha wages dropped by $5.2 \%$ and Maori wages by $11.5 \%$. However, when 'other' ethnicity is used as a variable in a regression estimate of log hourly earnings, the coefficient is found to be negative, but not statistically significant. Dixon suggests this may be because sample sizes are too small or because the independent effect of ethnicity on earnings is very weak. Results found in Dixon (2000) are somewhat different. When a regression is done using Household Economic Survey and Income Supplement data to estimate the effect of ethnicity on earnings, controlling for ethnic differences in education and experience, the coefficient found for the Pacific and other ethnic groups is negative, and although small, is statistically significant.

English literacy and labour market outcomes are examined by Chapple and Maré (2000) in a study which contains consideration of Pacific people. While numbers of Pacific people in their sample are small, literacy levels are relatively low, similar on average to the sole Maori group. Unlike sole Maori, the sample is almost exclusively urban and has a relatively low average age and marriage rate. Annual income is similar to the Maori ethnic group. About half Pacific Islanders are born outside New Zealand and a high number - again nearly half - spoke a Pacific Island language as their first language. Multivariate earnings and employment functions reveal no significant penalty for being of Pacific origin after controlling for age, education and literacy. However, controlling for various background factors like own education, parental education, learning difficulties and age, Pacific people appear to have a significantly lower level of English literacy.

Winkelmann and Winkelmann (1998) use census data from the period 1981 to 1996 to study the outcomes of Pacific migrants to New Zealand. Their research finds that the outcomes of Pacific immigrants deteriorated over the period between 1991 and 1996. In 1981 Pacific migrants had an employment rate similar to the rest of the population but by 1996 this had fallen to 15 percentage points below the average employment rate. Winkelmann and Winkelmann also find that Pacific migrants' income decreased relative to the rest of the population over the time period. In 1981 recent Pacific migrants earned approximately $55 \%$ of the average income. However, by 1996 this had dropped to approximately $41 \%$ of the average income. In particular, Winkelmann and Winkelmann (1998, pp. 6768) find that 'incomes tended to increase over time as immigrants' period of stay in New Zealand increased, the numbers show that relative incomes of successive incoming cohorts declined over time.'

Winkelmann and Winkelmann suggest that deteriorating employment outcomes may in part be due to the demographic characteristics of Pacific migrants. They find that Pacific migrants are on average much younger than other migrant groups and the New Zealand population. Pacific migrants have a larger than average number of families with dependent children and hold fewer qualifications than the rest of the New Zealand population. All these factors could contribute to lower rates of employment and income.

One thing that stands out clearly from this brief literature review is that many studies use solely descriptive data. No studies focus their attention primarily on Pacific people in the labour market, an observation which is not wholly surprising since Pacific people are a very small section of the labour market and ethnicity is far from the only interesting dimension of the labour market. Much of the literature employs cross sectional data obtained from one or more censuses. Multivariate studies consider Pacific outcomes only in passing, or used Pacific ethnicity as only one of a number of variables under consideration. In the case of Dixon's work, Pacific ethnicity was amalgamated with other ethnicity, to form a single 'other' ethnicity category, meaning that any result obtained will in part be explained by changes occurring in the other ethnic group.

Although the current study cannot hope to remedy all the gaps in our understanding of Pacific people in the labour market, it is hoped that it will add additional insight and information to the small existing body of research. This study makes use of the HLFS, which provides a "denser" picture of changes over time than the census can, as the census allows only one snapshot observation every five years, whereas data from the HLFS is available quarterly.

\section{How has Employment Disparity between Pa- cific and non-Pacific People Changed Over Time?}

According to HLFS data, the size and characteristics of the Pacific population in New Zealand have changed considerably between 1986 and 1999. The Pacific working age population has increased substantially from approximately 56,000 people to 134,000 people. The total Pacific share of the New Zealand working age population has increased from $2.4 \%$ to $4.7 \%$. The share of Pacific people in employment has also increased, but at a slower rate, from $2.4 \%$ to $4.0 \%$ of the total number of people employed. Therefore, in spite of an increase in employment share, the relative Pacific employment rate has fallen.

Figure 1 shows changes in employment rate disparity over the period, as measured by the percentage point difference between the Pacific and non-Pacific employment rates (employment divided by the working age population) from 1985-2000. 


\section{Figure 1. Employment Rate Disparity for Pacific Island Ethnic Group}

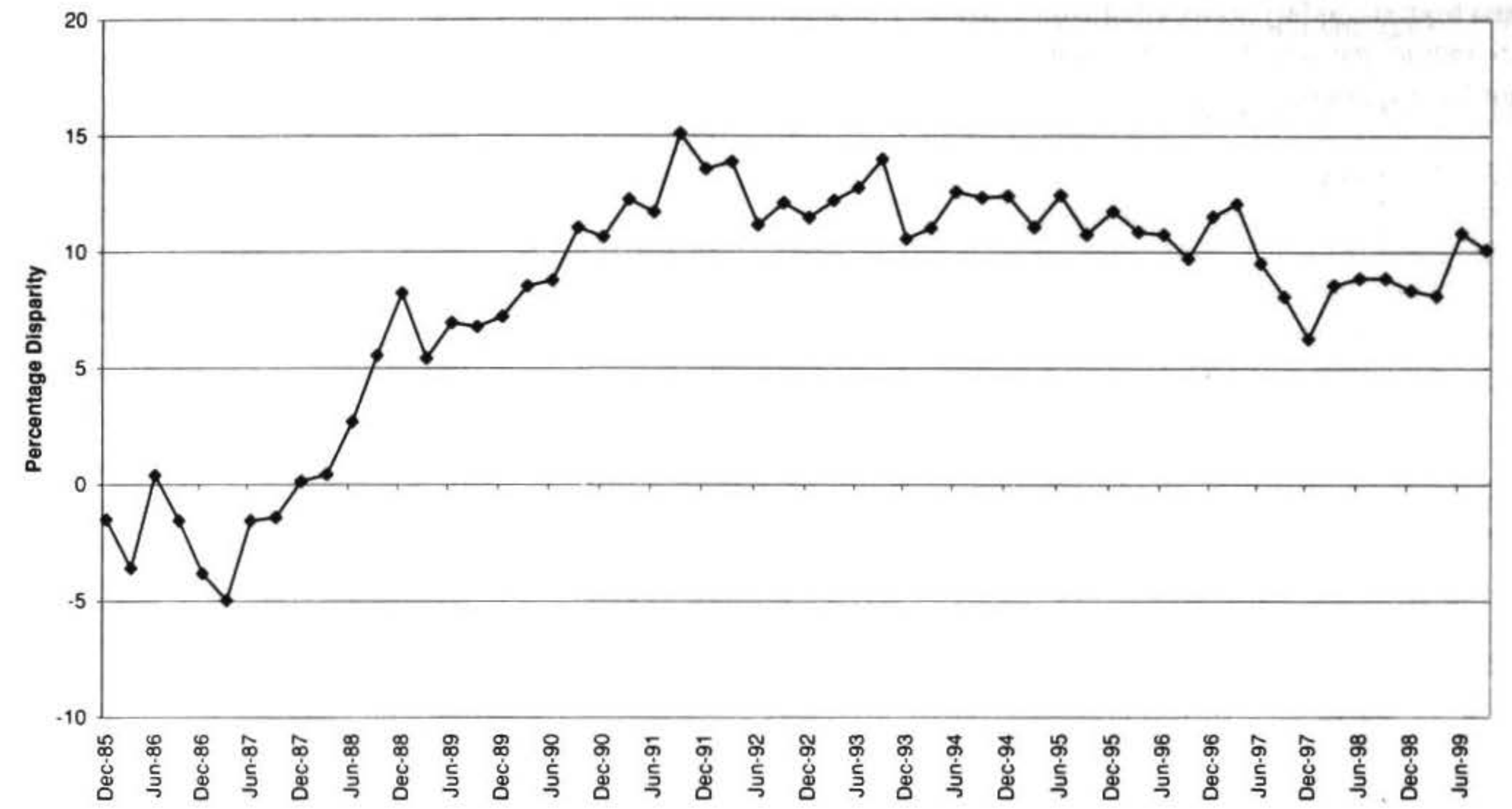

We can see from this figure that employment disparity for Pacific people has followed a broadly similar pattern to that of Maori (on the latter see Chapple and Rea 1998). Disparity rose dramatically over the late 1980 s, peaking in the early 1990s. From there on disparity has fallen considerably, but not back to levels prevailing in the mid-1980s. Disparity in employment rates remains economically and statistically significant. We now examine various factors that may provide some causal explanation for these trends in employment rate disparity.

\section{Why Has the Disparity between Pacific and non-Pacific People Changed Over Time? The Role of Education and Age Differences}

Differences between the Pacific and non-Pacific populations in average age and qualifications (the latter acting either as a signal of underlying capacity or as evidence of the acquisition of human capital) doubtless explain at least some of the cross-sectional gap in employment outcomes. The Pacific population is both younger than the non-Pacific population and has a lower level of qualifications on average. In 1999 the average age of the Pacific working age population was 36 years while the non-Pacific working age population averaged 43 years. Furthermore, in 1999, 39\% of the Pacific Island working age population had no qualifications and $25 \%$ had a tertiary qualification. This compares to $27 \%$ and $48 \%$ respectively for the non-Pacific population. The question we address here is whether these inter-ethnic differences have been changing in a manner which disadvantages the $\mathrm{Pa}$ cific group.

\section{Age Differences Stable or Narrowing}

There is no evidence that increased employment disparity has been caused by the growing relative youthfulness of the Pacific population. Indeed we can see from the Figure 2 that between 1987 and 1991, when employment disparity was widening, there was no clear pattern in the average age gap. The age gap appears to widen marginally between December 1988 and September 1989 but is closing thereafter. The closing of the age gap is inconsistent with increasing employment disparity, and if anything, it seems likely that further changes in the age gap will act to reduce employment disparity over the long run.

\section{Educational Differences Stable or Narrowing}

We can calculate the Duncan disparity index quarterly to summarise Pacific peoples' relative educational attainment over time. The Duncan index is chosen because it is straightforward to calculate and is a good simple readily interpreted measure for calculating disparity over more than two variables. In this case our Duncan index measures the percentage of the Pacific population that would have to have different qualifications in order to match the distribution of qualifications among the whole population (or vice versa). The index is calculated as follows:

$I_{D}=0.5 \times \Sigma_{i}|\mathrm{NP} / \mathrm{NP}-\mathrm{P} / \mathrm{P}|$

Where $I$ is the index measure, $\mathrm{i}$ is the level of qualifications held, NP is the number of non-Pacific people and P is the number of Pacific people.

The four different qualification levels summarised in the 


\section{Figure 2.Average Age of the Pacific Compared to the non-Pacific Population}

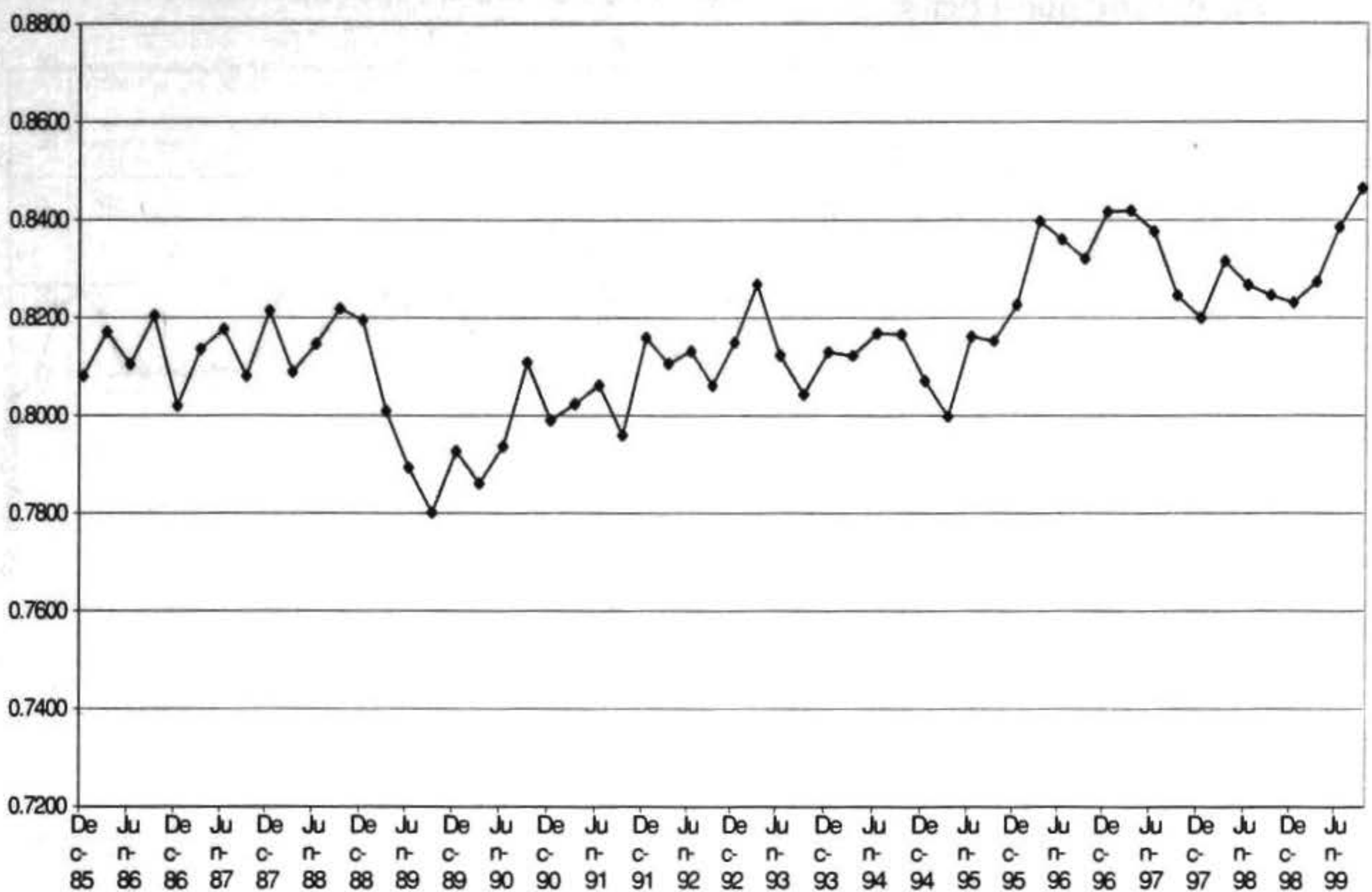

index are:

1. No qualifications;

2. Secondary school qualifications;

3. Post-secondary qualifications; and

4. Secondary and post secondary qualifications in combination.

Figure 3 shows the disparity in qualifications between 1985 and 1999 using the Duncan disparity index. At the start of the period about $25 \%$ of Pacific peoples needed to have a different educational qualification to have the same distribution of qualifications as non-Pacific peoples. By the end of the period this disparity was more like $21 \%$.

As with age differences, between 1987 and 1991, when employment disparity was widening the most, there is no clear pattern in the Duncan disparity index, which both rose and fell over this time. It therefore seems unlikely that a lack of qualifications on the supply side is driving the increase in employment disparity. Indeed, from the graph it seems that educational disparity is marginally falling: the Pacific population may slowly be catching up to the rest of the population in numbers of qualifications acquired.

\section{Migration and Pacific Labour Market Disparity}

Pacific population growth over the last 15 years has been driven by a combination of immigration and high rates of natural increase. It is well known that migrants take time to adjust into the labour market. Since immigration is possi- bly a force behind the observed strong growth in the $\mathrm{Pa}$ cific Island population, the obvious question to ask is to what extent the growth in employment disparity is driven by changes in the composition of the Pacific Island population toward recent migrants. In this section we briefly analyse data on employment rates and working age population, dependent on length of time lived in New Zealand.

\section{How Does the Length of Time Lived in New Zealand}

Affect Employment Outcomes?

Figure 4 shows the Pacific working age population broken into three groups; people born in New Zealand, people who migrated to New Zealand less than six years ago, and people who have migrated six or more years ago.

The Pacific working age population has more than doubled in the last fifteen years. This doubling equates to average annual working age population growth of $4.6 \%$, which is exceedingly rapid. Over the same time period the non-Pacific population had an average annual growth rate of $1.2 \%$. Most of the population growth for the Pacific group occurred in the group of overseas born Pacific people who have been here more than 6 years and in the New Zealand born population. If we look at Table 2 below we can see that these two groups accounted for more than $80 \%$ of total population growth. The population of recent migrants grew slowly up until 1991, but has fluctuated between 10,000 and 20,000 people since, suggesting that migration rates are diminishing.

Statistics New Zealand Demographic Trends 1999 (p. 20) shows similar figures for the total Pacific population. The 


\section{Figure 3.Duncan Disparity Index for Educational Qualifications between}

\section{Pacific and non-Pacific}

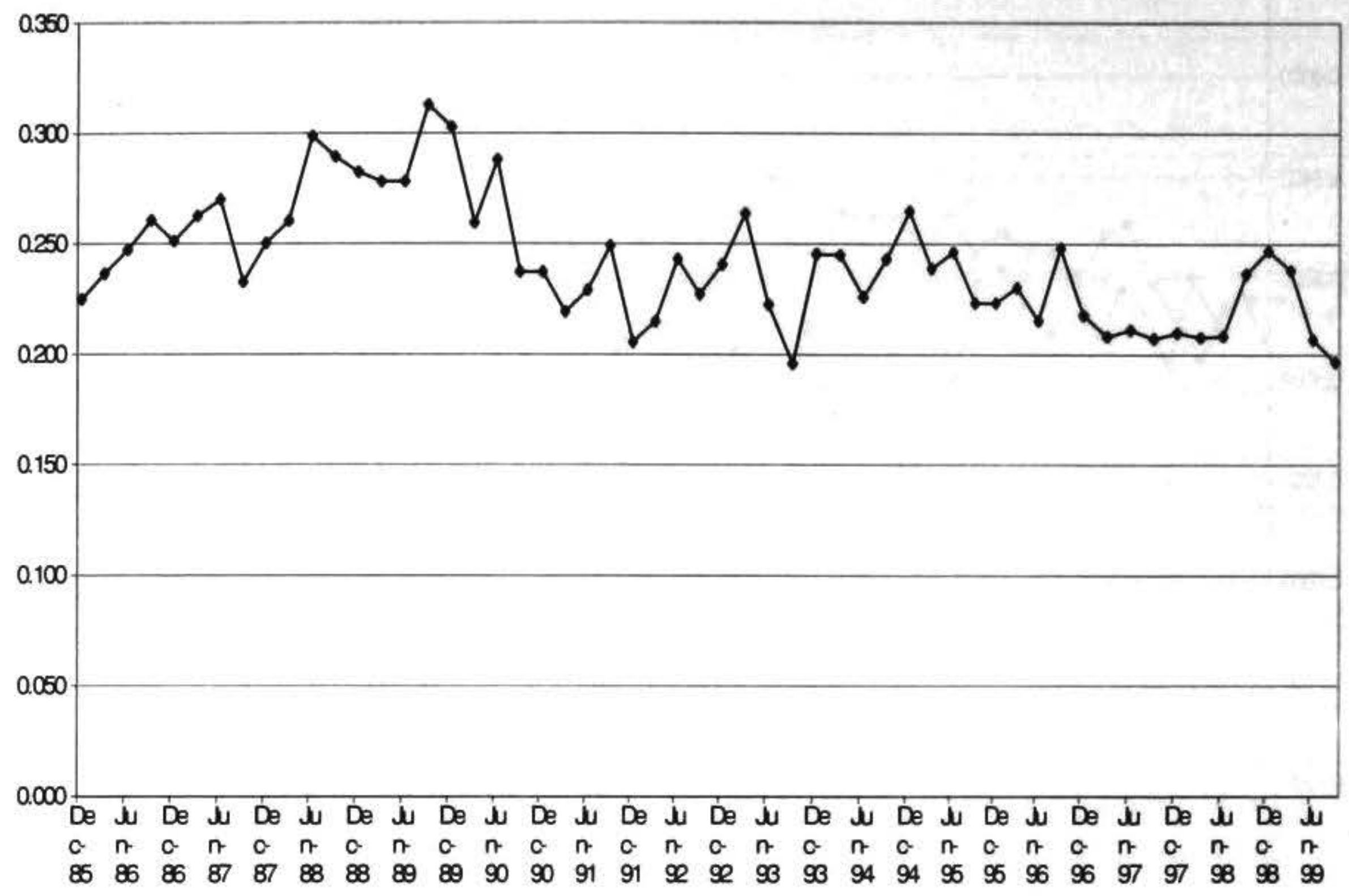

\section{Figure 4.Pacific Working Age Population Size by Length of Time lived in}

New Zealand

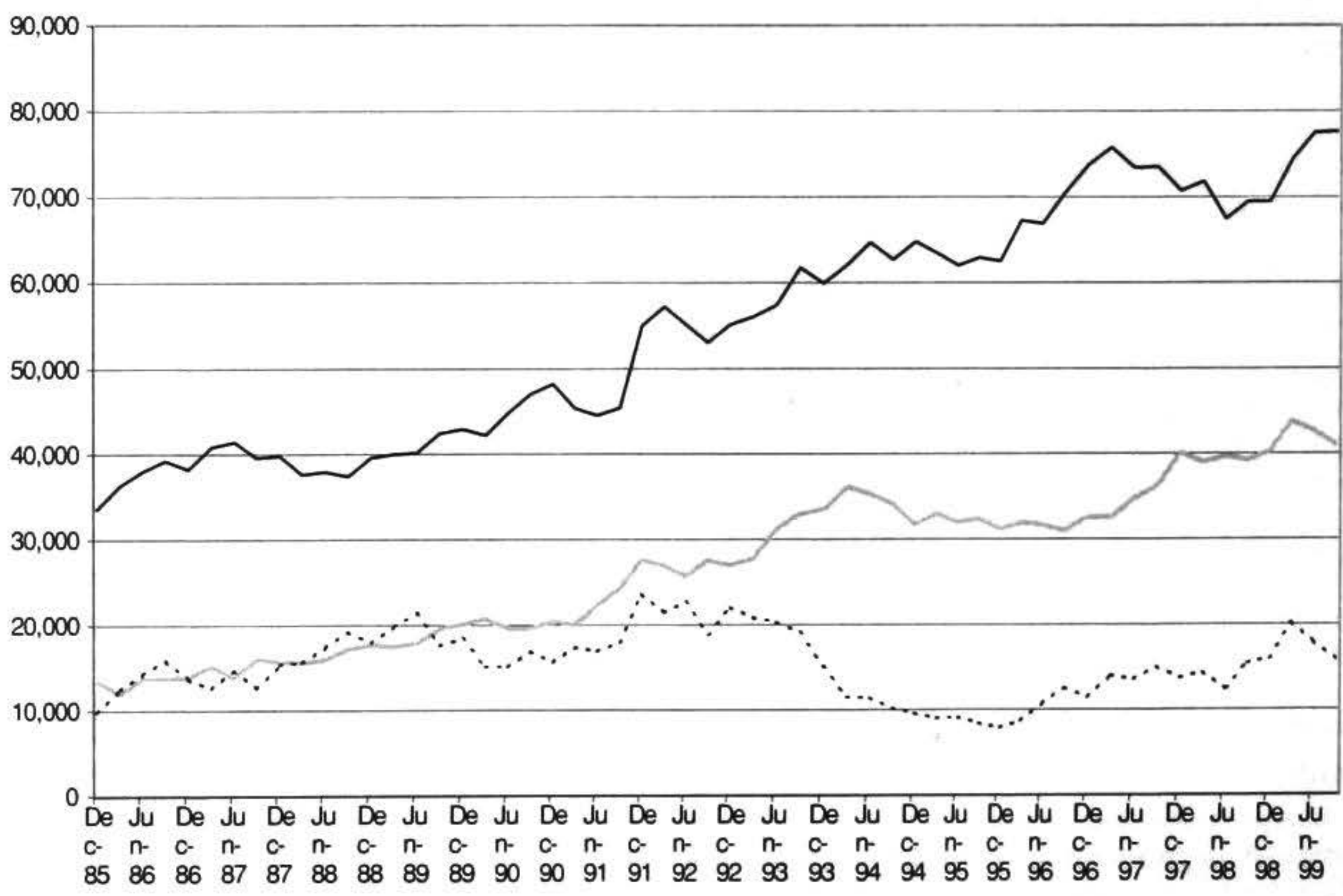

New Zealand Born.$\cdots$ Mgrant $1-5$ years ——Mgrant $6+$ years 
Figure 5. Employment Rate Disparity by Length of Time Lived in New Zealand

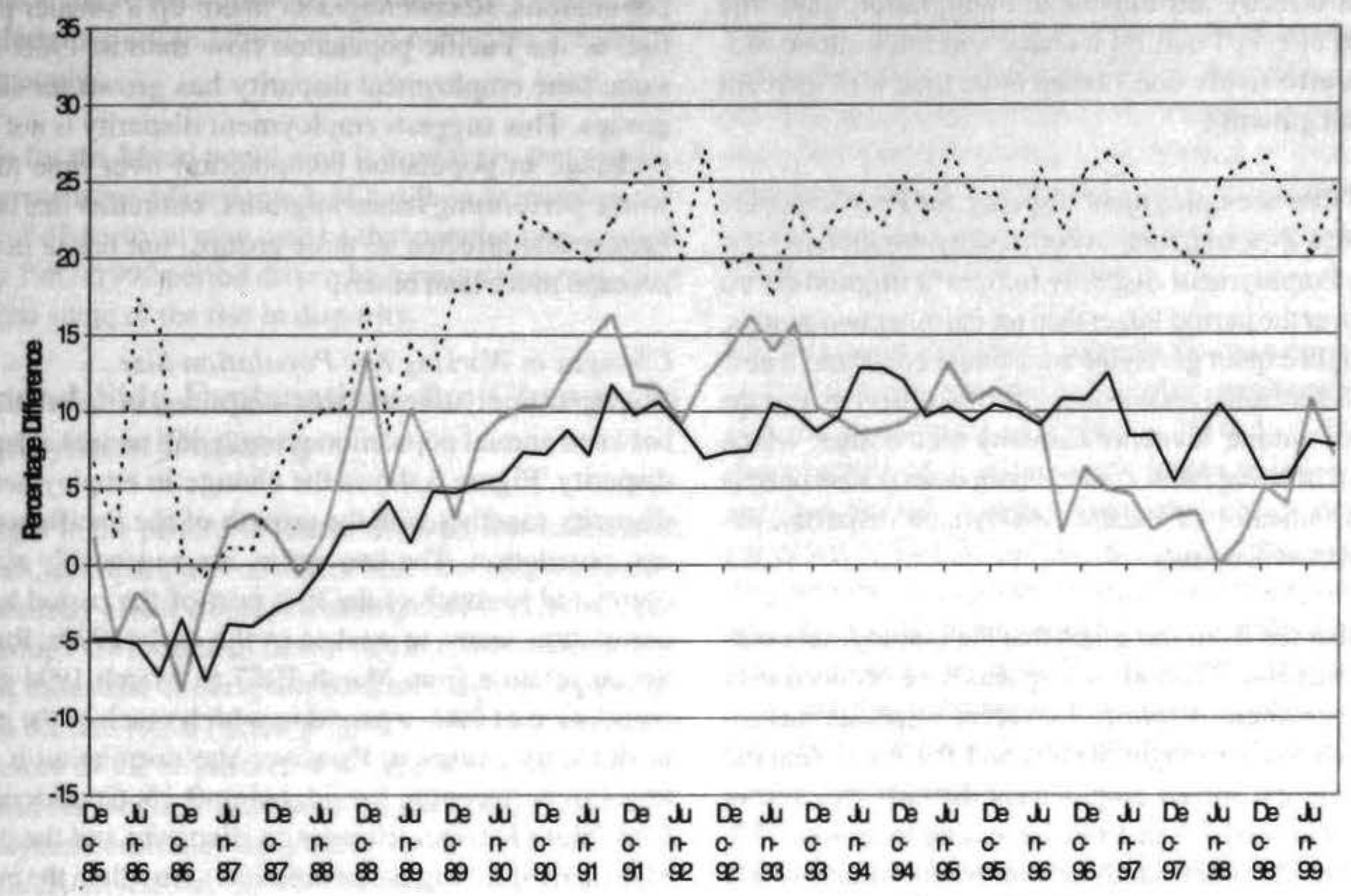

- NEEOm $\cdots \cdots$ Mgart 1-5ys - Mgart $6+\mathrm{ys}$

Figure 6. Growth in Pacific Employment Disparity and Working Age Population

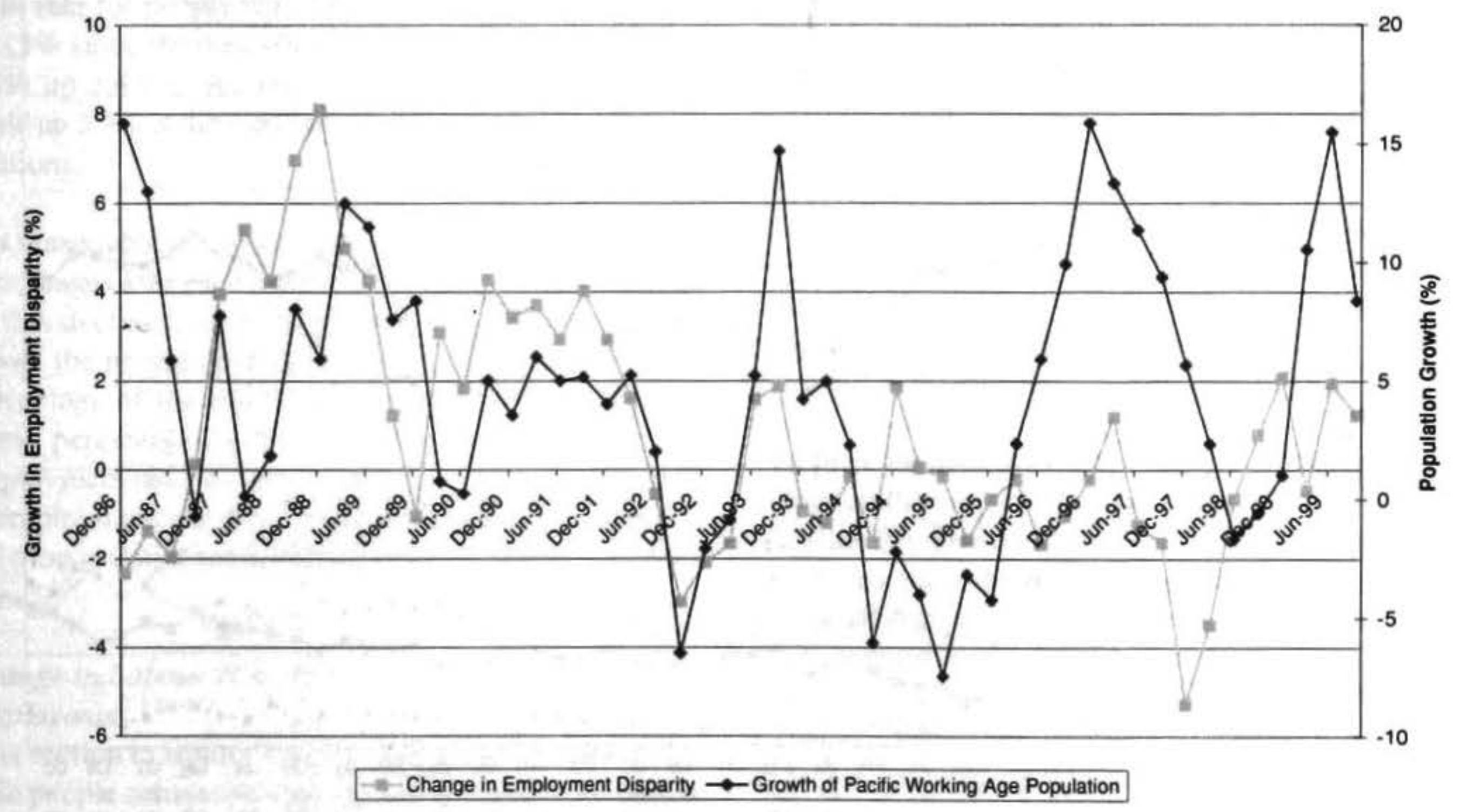


Pacific population has an annual growth rate of $3.3 \%$ compared to a growth rate of $1.0 \%$ for the total population. It also notes that 'less than one fifth of [Pacific population] growth is directly attributable to immigration' and 'the combined effect of natural increase and inter-ethnic mobility has effectively contributed more than $80 \%$ percent of the total growth'.

Figure 5 shows employment disparity for Pacific people split by New Zealand/foreign born and by duration in New Zealand. Employment disparity for recent migrants is on average over the period larger than for the other two groups, as one might expect given the adjustment costs into a new labour market facing recent migrants. The other two groups experience similar levels of disparity on average, which suggests that being New Zealand born or overseas born is not a key indicator of Pacific employment disparity, except for recent migrants.

We can also see from the graph that the employment outcomes of successive cohorts of migrants have declined over time. Employment disparity for recent migrants has increased relative to longer stayers and the New Zealand born. The graph shows employment disparity for recent migrants at around $7 \%$ in 1986, increasing to around $25 \%$ in 1999. On the other hand, for non-recent migrants and the New Zealand born disparity is around $8 \%$. The current cohort of recent migrants fares more poorly in the labour market than the cohort of migrants who were recent ten years ago did, a finding consistent with some of the results of Winkelmann and Winkelmann (1998).
Although recent migrants experience the greatest disparity in labour market outcomes, the population of recent migrants did not grow in number as much as the other two populations. Recent migrants make up a smaller proportion of the Pacific population now than in 1986. At the same time employment disparity has grown for all three groups. This suggests employment disparity is not due to a change in population composition over time towards worse performing recent migrants, but rather due to other factors that affected all three groups, but recent migrants perhaps more than others.

\section{Changes in Working Age Population Size}

The next supply side variable examined is the relationship between annual population growth and annual changes in disparity. Figure 6 shows the change in employment rate disparity together with the growth of the Pacific working age population. The two series are reasonably strongly correlated in much of the first part of the period but this correlation seems to weaken in the early 1990 s. Running the correlation from March 1987 to March 1994 gives a correlation of 0.45 , a period in which much of the growth in disparity occurred. However the correlation is much lower over the entire period, being 0.15 . Considering the correlation between changes in disparity and the growth of the recent immigrant population (growth in the population of Pacific people who have been less than five years in New Zealand), the correlations are stronger, especially for the shorter period (being 0.67 for the shorter period and 0.22 for the longer period).

\section{Figure 7. Percentage of Pacific Population Employed by Qualification}

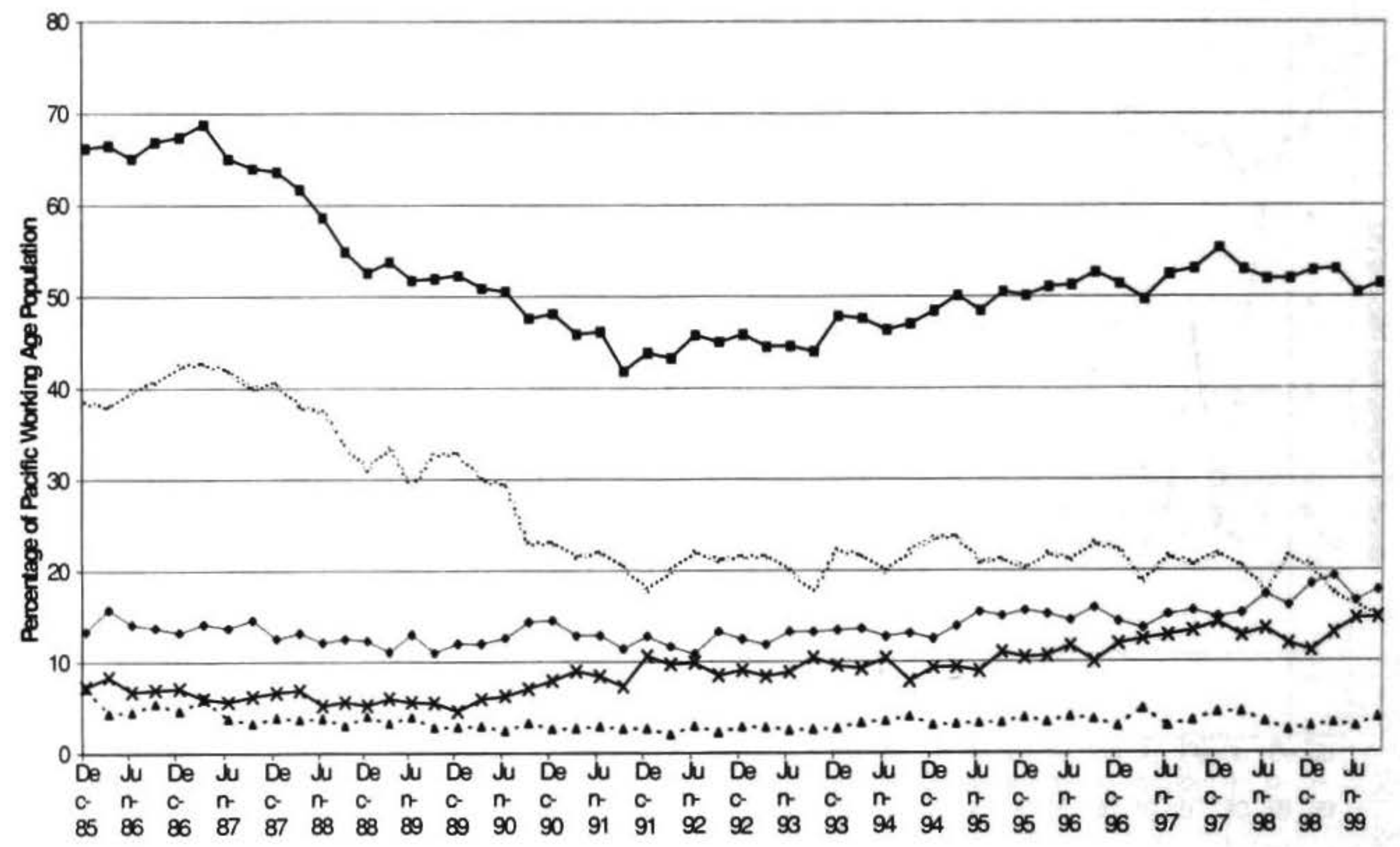

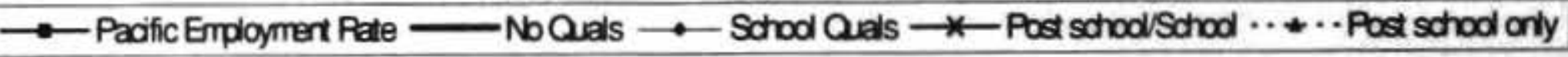


The pattern of these correlations suggests that while compositional shifts towards recent migrants may not be responsible for increases in disparity, at particular points in time an increased inflow of migrants may cause a relative deterioration in labour market outcomes for all $\mathrm{Pa}$ cific peoples.

While for the Maori population it is unlikely that population growth has played much of a role in explaining patterns of disparity, it may well be that population increases in the 1987-1992 period driven by immigration may have sparked some of the rise in disparity.

\section{Demand Side Explanations for Changes in Employment Disparity}

Changes in the pattern of labour demand across different regions, occupations, industries and educational qualifications may affect employment disparity if different ethnic groups are located in labour markets that differ across space, industrial or occupational groupings. It is possible that in the late 1980 s Pacific people were over-represented in sectors of the workforce that experienced contracting demand for labour. If this were the case, Pacific people's employment outcomes would have been disproportionately negatively affected by this demand contraction when compared with overall employment outcomes, which may have lead to an increase in employment disparity.

As an example, there was a strong decrease in demand for unskilled labour (measured by qualifications held) over the period 1986-99. Although we saw on the supply side that the level of qualifications held by Pacific people is becoming more similar to that of the rest of the population, there is still a larger than average number of Pacific people who do not have any qualifications. The employment rate for people with no qualifications has declined by $11 \%$ since the mid-1980s. At this time Pacific people made up $2.4 \%$ of the total working age population, but made up $3.7 \%$ of the working age population with no qualifications.

It is reasonable to suppose that a disproportionately large percentage of the Pacific population was adversely affected by this decline in demand for unskilled labour. Figure 7 shows the people employed with each qualification as a percentage of the total Pacific working age population. These percentages will add together to give the Pacific employment rate. We can see from this graph that the drop in employment rate does indeed match the quite substantial drop in employment among people with no qualifications.

\section{Change in Labour Demand and Pacific Share of Employment}

This section examines the percentage composition of $\mathrm{Pa}$ cific people across the workforce in 1986 for four dimensions: industry, occupation, educational qualifications and region. It then examines employment growth across these dimensions between 1986 and 1999 to see whether labour demand shifted in a way that was disadvantageous to the Pacific population. In particular we are looking to see whether demand for labour contracted in sectors in which Pacific people were over-represented. Below are four tables, one for each dimension. The second column of each table shows the percentage of Pacific people in each sector. The third column shows the change in employment over time for each sector. At the bottom of each table is a correlation measure, which shows the correlation between the percentage of pacific people in each sector and employment change in that sector.

Pacific people do indeed seem to be over-represented in sectors that showed slow or negative employment growth over the period between 1986 and 1999. In 1986, 5.6\% of those employed in the manufacturing industry were $\mathrm{Pa}$ cific people. This was the largest percentage share of employment of Pacific people in any industry, and was the only industry to experience negative employment growth over the period under consideration. Pacific people were also over-represented in the Transport and Communications industry relative to other groups, and this industry experienced the next lowest employment growth after the manufacturing sector.

A similar pattern is seen on examining Pacific representation in different occupational groupings. Pacific people are over-represented relative to the rest of the population in the Production and Related Workers Group, which shrank by $19.3 \%$ between 1986-1999. Very few Pacific people were employed in the Administrative and Managerial Workers Group, which was the occupational grouping that showed the highest employment growth over the fifteen year period. Indeed, rounded to one decimal place, the percentage of Pacific people employed in this occupational grouping is zero.

The figures for employment growth by educational qualification groups also show a similar trend. The two groups that show the largest drop in employment were people with Post-school qualifications only, and people with no qualifications. Pacific people are over-represented in the group with no qualifications, and the employment rate for this group declined by $10.9 \%$ over the time period. Pacific people are also under-represented in the group of people who have school and post-school qualifications, which had the smallest drop in employment rate, only $2.4 \%$.

The final variable considered is region. It does not seem as though there is any clear pattern of Pacific over-representation in regions with low employment growth. Pacific people are under-represented both in the region with the largest drop in employment rate and the region with the smallest drop in employment rate over the time period. Indeed, the correlation between the variables for this dimension is very small, $-11.3 \%$, so it is unlikely that changes in labour demand by region increased Pacific disparity unduly.

The correlations between the variables are stronger for the other three dimensions. Indeed, the correlations between 
the variables for industry, occupation, and education at $-69.1 \%,-68.6 \%$ and $68.0 \%$ suggest that Pacific people were over-represented in sectors of the labour market that contracted between 1986 and 1999 . To find out the extent to which this occurred, and which sectors had the most influence, we now conduct a more formal decomposition of the employment rate gap.

\section{Estimates of Sectoral Influence on Employment Disparity}

We more formally examine the extent to which Pacific employment disparity can be attributed to over-representation in declining industries, regions and occupations, and among people with few or no qualifications. We conduct a decomposition of changes in the employment rate gap, taking into account the different Pacific population representation across industry, region, occupation and educational qualifications, and the growth in working age population share over the period. The formulae used to calculate this decomposition are contained in Chapple (1999). The following table gives the results.

Two different time frames are used. The first set of numbers is calculated for the period 1986-1991, when the total rise in employment disparity was greatest, and the second set of numbers estimates the employment disparity over the full fifteen year period. The percentages given above cannot be added together because sectoral changes may be related. For example, part of the gap attributed to educational qualifications may be because particular industries that employ large numbers of unskilled workers have decreased their demand for labour. A change such as this will have an effect on disparity attributable to both the industry and education sectors.

Once again we can see that education, occupation and industry explain a large amount of the rise in employment disparity. Occupation seems to account for a large part of the increase in employment disparity for the period between 1986 and 1990. The most important factor over the whole time period seems to be shift in demand by education, which explains more than $10 \%$ of the rise in disparity. This would suggest that demand for labour in unskilled occupations has dropped substantially and a focus on improving educational outcomes to ensure that Pacific people are not over-represented in unskilled groups is very important. On the other hand, region does not seem to explain increasing Pacific employment disparity. In fact, it seems as if changes in regional demand may have moved in a way that could have decreased disparity in the absence of other factors. This could once again be the result of a high degree of urbanisation, as few Pacific people live in the region which recorded the largest drop in employment.

\section{Conclusion}

Over the last 15 years Pacific people have seen an average deterioration in their labour market outcomes in the labour market compared to non Pacific people. Today $\mathrm{Pa}$ cific people have lower employment rate than non Pacific people. However, this has not always been the case. In 1986 the Pacific employment rate was higher than the employment rate for the rest of the population. Pacific employment disparity rose dramatically at the end of the $1980 \mathrm{~s}$, to peak at around $15 \%$ at the end of 1991 . It has since been slowly falling to the present level of approximately $8 \%$. This note has used cross-tabulated data from the Household Labour Force Survey for the last 15 years to examine possible explanations for changing disparity in employment outcomes between Pacific and non-Pacific peoples.

The supply side variables of changing relative age and educational qualififcations do not seem to provide much explanation for worsening employment outcomes. In fact, on the supply side there is evidence to suggest that Pacific people are becoming more similar to non-Pacific people, which may have helped to reduce employment disparity. The median age gap is slowly narrowing, as is the disparity in educational qualifications. This suggests that Pacific outcomes relative to the rest of the population could improve over the long run and could help to explain the small decrease in disparity throughout the 1990s.

Changes in the relative distribution of migrant status did not explain changes in employment disparity over the time period. Longer-term migrants and the New Zealand born both showed patterns of employment disparity similar to the total change over time. Disparity for recent migrants was higher and continued to be high throughout the 1990s. However the population of recent migrants did not grow as much as the other two groups, suggesting that employment disparity could not be explained by growing numbers of recent migrants. There was some evidence, however, that in certain periods population growth of recent migrants was correlated with rises in employment disparity.

Changes in labour demand appeared to have a strong influence. By conducting an employment rate gap decomposition it was found that much of the change in employment disparity could be explained by changing labour demand in sectors in which Pacific people were over-represented. In particular there was a large decrease in demand for workers with low or no educational qualifications, workers in the manufacturing industry and the occupational grouping of production and related workers. Labour demand by region, on the other hand, developed in a way that decreased rather than exacerbated Pacific employment disparity.

Overall, evidence suggests that labour demand changes in conjunction, perhaps with immigration shocks, were responsible for increasing employment disparity over the period. Specifically, in the late 1980s and early 1990 s there were decreases in labour demand in sectors that Pacific people were over-represented in, such as workers with no qualifications, production and related workers, and workers in the manufacturing industry. At the same time, there were bursts of immigration of Pacific people into the low 
skilled labour market. Avoiding supply shocks as a consequence of immigrationis more amenable to policy intervention than avoiding demand shocks to employment composition.

From the early 1990s onward it seems that Pacific employment disparity has been falling, albeit slowly. One explanation for this could be that Pacific people are becoming more similar to the rest of the population on the supply side. For example, the mean age of Pacific people is catching up to the total population mean age. Perhaps more importantly, the distribution of educational qualifications is becoming more like that of the rest of the population, which suggests that in future Pacific people will move away from lower skill sectors of the economy and therefore be less vulnerable to labour demand shocks. However, this process is very slow in comparison to the otherwise similar trends for Maori (Chapple 1999).

\section{Future Research}

In terms of future research, it would be of interest to look more closely at demographic variables, in light of our results on the influence of population size on the supply side. It is difficult to say what is happening here as we only used a simple correlation measure. More in depth work would be useful. For example, it would be interesting to examine why population size and employment disparity were correlated in the late 1980s and why this correlation seems to diminish in the 1990s.

\section{Notes}

1 Comparable Maori figures for hourly earnings were $83.9 \%$ for men and $86.7 \%$ for women. The data come from the pooled 1997/8 Income Supplements. We thank our colleague Sylvia Dixon for providing us with this data.

2 The HLFS defines working age population as all people aged between 15 and 59 .

3 Employment rate measures the percentage of the working age population that is employed and is equal to the number of people employed divided by the working age population multiplied by 100 .

4 The HLFS defines ethnicity in the following hierarchical way: the head of the household chooses up to three ethnic groups for each member of the household. If people are classified in more than one ethnic group, then the following hierarchy applies: Maori, Pacific people, Other ethnic group, Pakeha/European. Thus Maori and Pacific counts as Maori, but Pakeha/European and Pacific counts as Pacific.

5 For details on the Duncan index see Chapple and Rea (1998). of convergence in qualifications for the mixed and sole Maori population.

7 Occupational growth is only measured for the period between 1986 and 1990. This is because the Statistics New Zealand classification of occupations changed in 1990, meaning we have two sets of observations which are not strictly comparable, one from 1986 to 1990 , and one from 1991 to 1999 . The first half of the series only is considered as this was when the largest drop in Pacific employment occurred.

8 Except occupation, which is only available for the period 1986-1990. See footnote 13 for details.

\section{References}

Chapple, S. (1999) Explaining Patterns of Disparity between Maori and non-Maori Employment Chances. Labour Market Bulletin, Forthcoming,

Chapple, S. and Maré, D. (2000) Literacy formation and its influence on earnings and jobs. unpublished Department of Labour draft.

Chapple, S. and Rea, D. (1998) Time Series Analysis of Disparity between Maori and non-Maori Labour Market Outcomes. Labour Market Bulletin. 1\&2: 127-144.

Cook, L. Didham R. and Khawaja, M. (2000) On the Demography of Pacific People in New Zealand. Demographic Trends 1999. Wellington: Statistics New Zealand, January. .

Dixon, S. (1996) The Distribution of Earnings in New Zealand 1984-94. Labour Market Bulletin. 1: 45100.

Dixon, S. (2000) Pay Inequality between Men and Women in New Zealand. Wellington: Department of Labour.

Fletcher, M. (1995) Pacific Island Peoples in the Labour Market. Labour Market Bulletin. 1: 124-135.

Krishnan, V. (1994) The Challenge of Change: Pacific Islands Communities in New Zealand, 1986-1993. Wellington: Institute of Social Research and Development.

Ministry of Pacific Island Affairs (1999) The Social and Economic Status of Pacific People in New Zealand. Wellington: Ministry of Pacific Island Affairs.

Statistics New Zealand (1997) 1996 Census of Population and dwellings: Ethnic Groups. Wellington: Statistics New Zealand,. 
Statistics New Zealand (2000) Demographic Trends 1999. Wellington: Statistics New Zealand.

Te Puni Kokiri (1998) Progress Towards Closing Social and Economic Gaps between Maori and nonMaori. Wellington: Te Puni Kokiri.

Winkelmann and Winkelmann (1998), Immigrants in New Zealand: A Study of their Labour Market Outcomes, Department of Labour Occasional Paper 1.

\author{
Authors \\ Janet Humphris \\ Trainee Analyst \\ Labour Market Policy Group \\ Department of Labour \\ PO Box 3705 \\ Wellington \\ Janet.humphris@lmpg.dol.govt.nz \\ Simon Chapple \\ Chief Economist \\ Ministry of Social Policy \\ Private Bag 39993 \\ Wellington \\ Simon.chapple006@mosp.govt.nz
}

